\title{
Suppressive Control of the Crustacean Pyloric Network by a Pair of Identified Interneurons. I. Modulation of the Motor Pattern
}

\author{
Jean-René Cazalets, Frédéric Nagy, and Maurice Moulins \\ Laboratoire de Neurobiologie et Physiologie Comparées, CNRS et Université de Bordeaux I, F-33120 Arcachon, France
}

\begin{abstract}
A pair of identified neuromodulatory neurons, the pyloric suppressor (PS) neurons, can individually and strongly modify the activity of the pyloric network in the stomatogastric nervous system of the lobster Homarus gammarus. The PS neurons are identified by the location of their somata in the inferior ventricular nerve, their axonal projections, and their effects on pyloric network activity in vitro. Discharge of a PS neuron evokes large EPSPs in the pyloric dilator (PD) neurons and a long-lasting cessation of rhythmic activity in the neurons that control movements of the pyloric filter: PD, lateral pyloric (LP), and pyloric (PY). This cessation of rhythmic activity can outlast by several 10 s of seconds a brief discharge of PS lasting only a few seconds. The different neurons of the pyloric filter do not exhibit the same sensitivity to the suppressive effects of PS, with the LP neuron being the most sensitive. Tonic discharge in PS induces graded alterations in the pyloric pattern, depending on its firing frequency. At low $(<5 \mathrm{~Hz}$ ) discharge frequencies, PS provokes changes in phase relationships and duration of bursting in pyloric neurons. A slight increase in PS frequency suppresses the rhythmic activity of some pyloric neurons, resulting in a switch from a triphasic to a biphasic pattern. At higher $(>10 \mathrm{~Hz})$ PS firing trequencies, rhythmic activity in all the pyloric neurons, including the pacemakers (PD, anterior burster), is abolished, except in cells (ventricular dilator, inferior cardiac) controlling the pyloric valve. We conclude that a central pattern generator is not only subject to activating modulatory control, but may also be the target of suppressive inputs that are themselves able to provoke functional reconfigurations of the network.
\end{abstract}

It is now widely accepted that most rhythmic motor patterns are generated by discrete groups of neurons called central pattern generators (CPGs). Initial investigations studied how these neuronal networks are organized with respect to the identification and nature of component elements and their synaptic relationships. However, more recent research has focused on how CPGs are controlled and modulated to produce different patterns that underlie behavioral flexibility observed in vivo. Most of these studies have used indirect (pharmacological and immunohistochemical) methods and have revealed that a wide range of

\footnotetext{
Received Dec. 7, 1988; revised May 8, 1989; accepted June 23, 1989.

We thank R. Harris-Warrick, B. Johnson, P. Katz, J. Simmers, and A. J. Terney for critical comments on early drafts of this manuscript, and J. Simmers for help in preparing the final English version. This work was supported by a Ministère de la Recherche et Technologie Grant $85-\mathrm{C}-1152$ to M.M.

Correspondence should be addressed to M. Moulins at the above address.

Copyright (C) 1990 Society for Neuroscience $0270-6474 / 90 / 100448-10 \$ 02.00 / 0$
}

putative neurotransmitters can finely control the activity of CPGs in both vertebrates and invertebrates alike (for review, see Harris-Warrick, 1988). By contrast, there are relatively few known examples of neurons identified electrophysiologically and shown to exert a modulatory control over CPG networks. In trying to understand the cellular mechanisms by which identified modulatory neurons can influence a CPG circuit, we have studied one of the best-known small-sized CPGs, the pyloric network of the crustacean stomatogastric ganglion (STG).

From a variely of studies on in vilro preparations, the rhythmic pattern produced by the pyloric CPG has been shown to depend on the oscillatory properties of the neurons themselves and on the synaptic connections between these neurons (Selverston and Moulins, 1987). It is also clear that the intrinsic ability of the pyloric neurons to produce regenerative bursts of action potential is dependent on "permissive" (activating) control exerted by modulatory inputs to the STG. Several putative activating neurotransmitters (octopamine, serotonin, dopamine, proctolin, FMRFamide, acetylcholine) have been identified (for review see Marder, 1987), and a few neuronal elements that modulate the pyloric output have been identified (Nagy et al., 1981; Russell and Hartline, 1981; Dickinson and Nagy, 1983; Nagy and Dickinson, 1983; Katz and Harris-Warrick, 1987; Nusbaum and Marder, 1987). These identified inputs all have effects that induce or enhance the rhythmic activity of the pyloric network. Recently, however, indirect evidence has suggested that this network is also the target of a suppressive modulatory control that would diminish or abolish rhythmic pyloric activity (Cazalets et al., 1987a).

We now directly demonstrate that the pyloric CPG is subject to "suppressive" control. We have identified 2 neurons, called the pyloric suppressor (PS) neurons, which project to the pyloric network and whose discharge dramatically suppresses pyloric rhythmic activity. In the present paper this suppressive effect is analyzed at the level of network activity, while the cellular mechanisms involved are considered in the accompanying paper (Cazalets et al., 1990). A preliminary report of some of these results has been published (Cazalets et al., 1987b).

\section{Materials and Methods}

Experiments $(n=33)$ reported here were performed on the adult European lobster Homarus gammarus, although identical results have been obtained from the American lobster Homarus americanus. Animals were maintained in aerated flowing sea water until use. The experimental saline (Miller and Selverston, 1982) consisted of (in mM): $479 \mathrm{NaCl}$, $12.74 \mathrm{KCl}, 13.7 \mathrm{CaCl}_{2}, 10 \mathrm{MgSO}_{4}, 3.9 \mathrm{Na}_{2} \mathrm{SO}_{4}$, and 5 HEPES and was adjusted to $\mathrm{pH} 7.45$ with $\mathrm{HCl}$ or $\mathrm{NaOH}$.

Electrophysiology. The stomatogastric nervous system was removed 
A

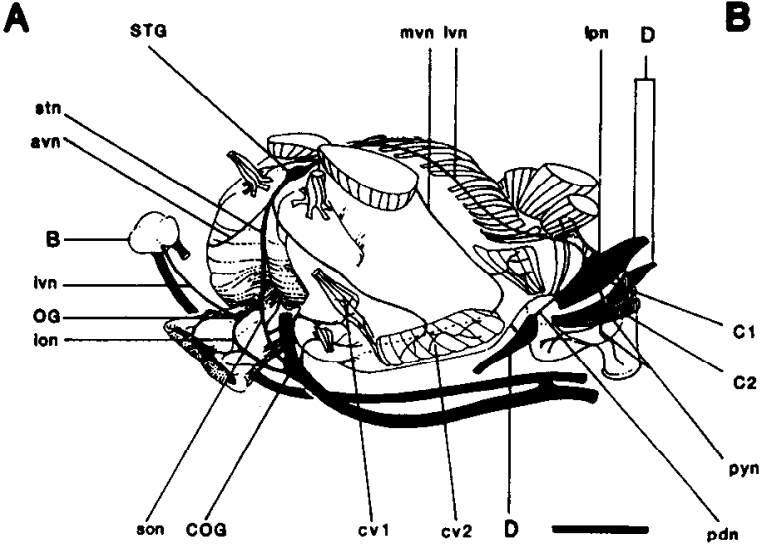

C

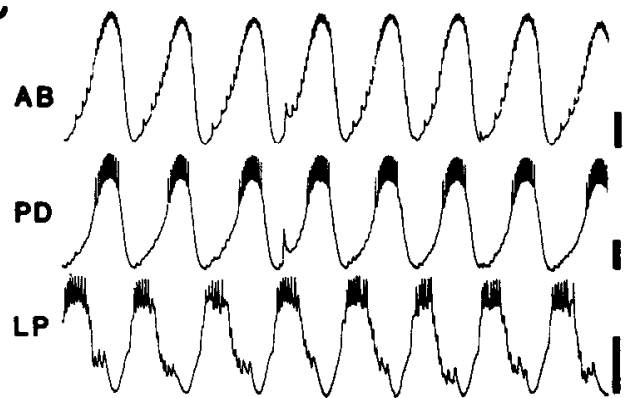

PY
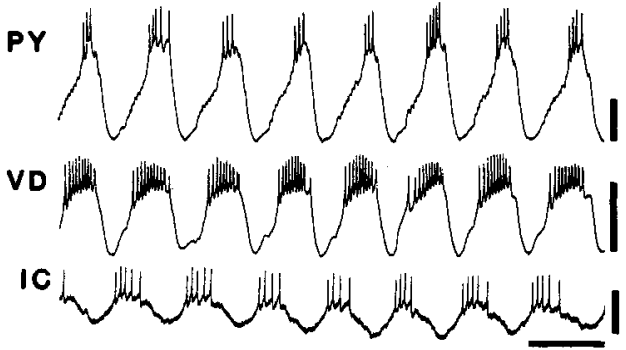

B

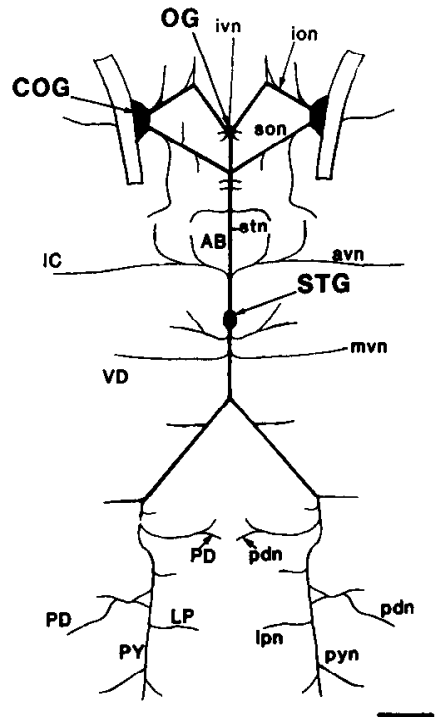

D

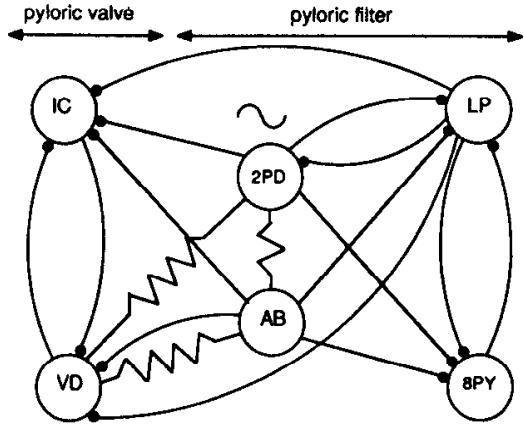

Figure 1. The stomatogastric nervous system and the pyloric network. $A$, Left anterolateral view of the stomach showing the stomatogastric nervous system in situ. Only principal muscles and nerves have been drawn. $B$, Diagram of the isolated nervous systcm preparation. The names of individual pyloric neurons are indicated at the level of the nerve tract that carries their axon. $C$, Simultaneous intracellular recordings from the 6 types of pyloric neuron. $D$, Synaptic wiring diagram of the pyloric network. Black dots and resistors indicate inhibitory and electrical synapses, respectively. $A B$, anterior burster neuron; $a v n$, anterior ventricular nerve; $B$, brain; $C I$, constrictor muscle 1 (innervated by $L P$ ); $C 2$, constrictor muscle 2 (innervated by the PY neurons); $C O G$, commissural ganglion; $c v$, cardiac ventricular muscle; $D$, dilator muscle; $I C$, inferior cardiac neuron; ion, inferior esophageal nerve; ivn, inferior ventricular nerve; $L P$, lateral pyloric neuron; $l p n$, lateral pyloric nerve; $l v n$, lateral ventricular nerve; $m v n$, median ventricular nerve; $O G$, esophageal ganglion; $P D$, pyloric dilator neuron; $p d n$, pyloric dilator nerve; $P Y$, pyloric neuron; $p y n$, pyloric nerve; son, superior esophageal nerve; $S T G$, stomatogastric ganglion, $\sin$, stomatogastric nerve; $V D$, ventricular dilator neuron. Horizontal scale bars: $1 \mathrm{~cm}, 1 \mathrm{sec}$; vertical scalc bars: $A B, P D, L P, P Y, V D, 10 \mathrm{mV} ; I C$, $5 \mathrm{mV}$. from the dorsal part of the stomach (Fig. $1 A$ ), pinned in a Sylgard-lined petri dish, and continuously perfused with oxygenated saline maintained at $15^{\circ} \mathrm{C}$. The stomatogastric nervous system consists of the paired commissural ganglia (COGs), esophageal ganglion (OG), STG, and their interconnecting and other related nerves (Fig. $1 B$ ). The STG and OG were desheathed to allow intracellular recordings from the cell bodies of pyloric and PS neurons (see below). Extracellular recordings from nerves were performed with platinum wires insulated with Vaseline. The same electrodes were used to stimulate the nerves via a Grass S88 stimulator. Intrasomatic recordings from neurons were made with glass microelectrodes filled with $3 \mathrm{M} \mathrm{KCl}(R=10 \mathrm{M} \Omega)$ and each was connected to a $\$ 7100$ WPI electrometer. Neurons were identified as described by Robertson and Moulins (1981) and Cazalets et al. (1987a). Unless specified, the same electrode was used for voltage recording and intrasomatic current injection via a bridge circuit. Electrophysiological records were stored on a MP5521 Schlumberger FM tape recorder and visualized on either a Tektronix 5113 oscilloscope or a Gould ES1000 electrostatic recorder.

Owing to difficulty in impaling the cell body of PS, we often used extracellular stimulation of its axon in the proximal region of the inferior ventricular nerve (ivn). For this, the OG and the proximal part of the ivn were desheathed to visualize the 2 PS somata, and then a platinumstimulating electrode was carefully placed between the somata and the OG.

Cobalt backfilling. To establish the axonal geometry of the PS neurons, a Vaseline well was built around the cut end of a selected nerve in an isolated preparation and filled with cobalt chloride $(8 \%)$. The preparation was stored for $24-28 \mathrm{hr}\left(4^{\circ} \mathrm{C}\right)$ to allow cobalt migration. The cobalt ions were precipitated with ammonium sulfide and the preparation was then fixed in paraformaldehyde $(4 \%)$, cleared in methyl salicylate, and observed under light microscope (Pitman et al., 1973).

\section{Results}

\section{Pyloric network of Homarus}

The pyloric network in the STG of Homarus consists of 14 neurons divided into 6 major cell classes (Fig. 1C). The pyloric rhythmic output (frequency, $0.2-1.2 \mathrm{~Hz}$ ) results from the sequential activation of these 6 types of neurons. The synaptic relationships that determine this coordinated pattern are shown in the network wiring diagram of Figure $1 D$. The 2 pyloric dilator (PD) neurons that drive the PD muscles (Fig. $1 A$ ) are electrically coupled with the anterior burster $(A B)$ interneuron whose axon projects to the COGs. These 3 neurons generally display synchronous activity and can usually be considered a functional unit. Moreover, as they have the strongest oscillatory capabilities, they are considered to act as the primary pacemakers for the entire pyloric network (Miller, 1987; Bal et al., 1988). They rhythmically inhibit all other pyloric neurons, including the lateral pyloric neuron (LP, innervating the early constrictor muscle C1, Fig. $1 A$ ), the PY neurons (innervating the late constrictor muscles $\mathrm{C} 2$ ), the ventricular dilator neuron (VD, innervating the dilator muscle cvl of the pyloric valve), and the inferior cardiac neuron (IC, innervating the constrictor muscle cv2 of the pyloric valve). Only minor differences are evident between the pyloric networks of Homarus and Panulirus (Miller and Selverston, 1982), the main one being an inhibitory connection from LP to IC, which is absent in Panulirus. However, Homarus 

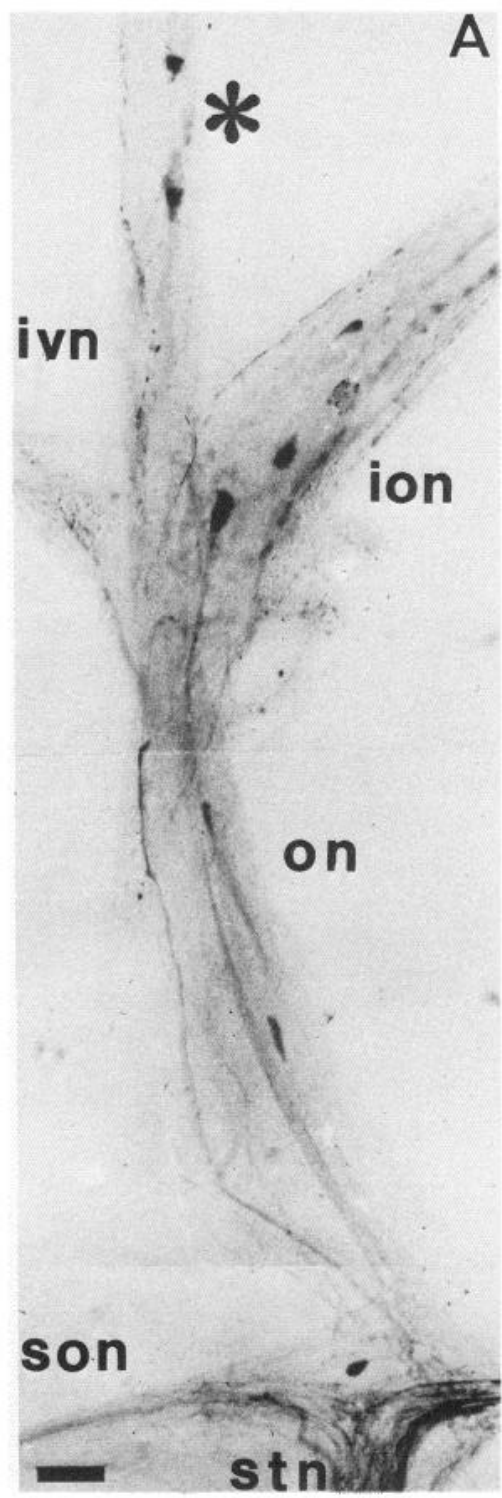
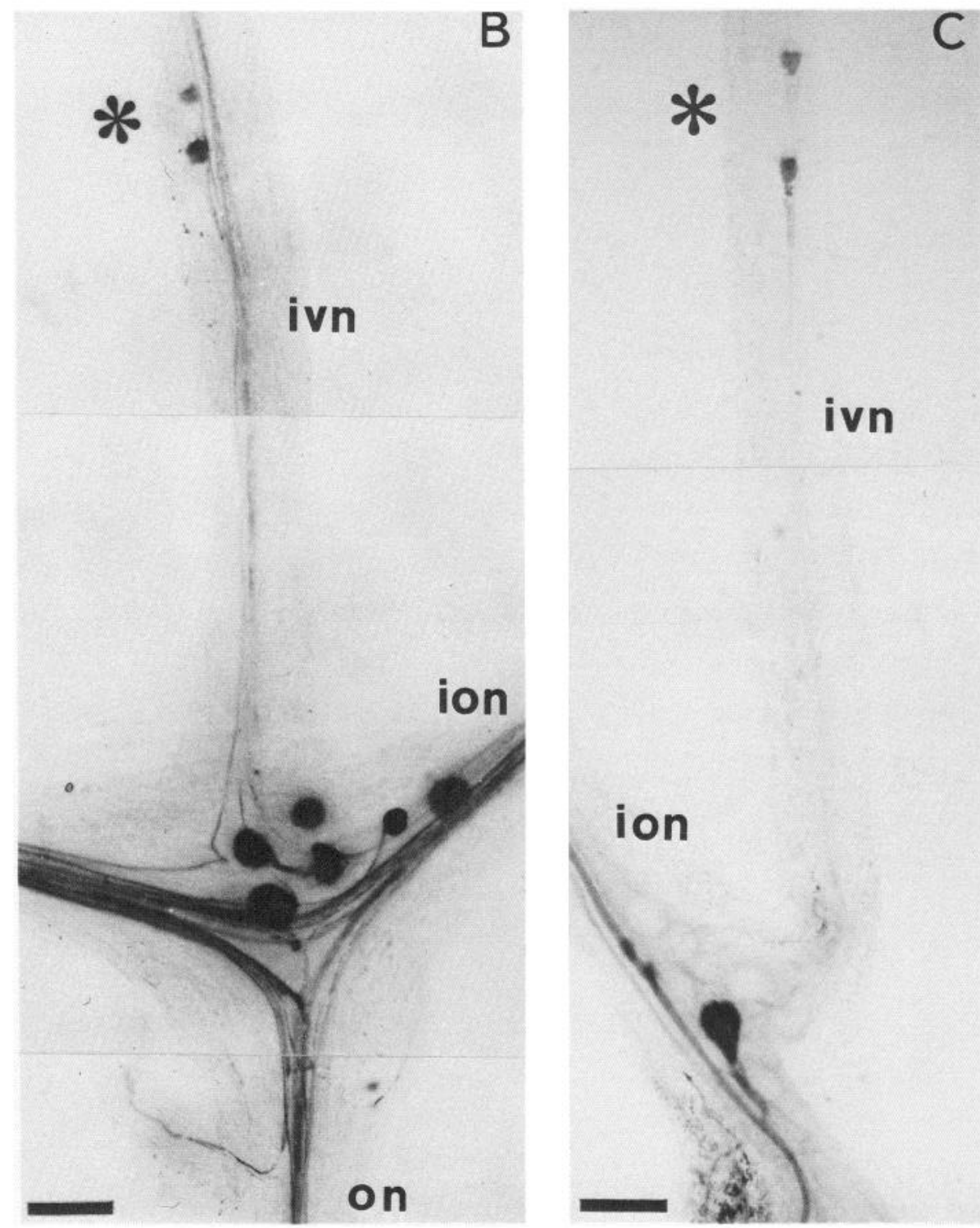

Figure 2. Morphological identification of the PS neurons. Cobalt chloride backfill of the superior esophageal nerve (son, A), the inferior esophageal nerve (ion, $B)$, and the stomatogastric nerve $(\operatorname{stn}, C)$. The cell bodies of the 2 PS neurons $($ stars $)$ are characteristically located in the proximal inferior ventricular nerve $(i v n)$, from where they send processes into both esophageal nerve $(A, B)$ and the $\sin (C)$. Horizontal scale bars, $150 \mu \mathrm{m}$.

lacks some secondary connections (VD to LP, PY to IC, and VD to PY), which exist in Panulirus.

\section{PS neurons}

The ivn of Homarus contains 2 cell bodies (Fig. 2) located 1-2 $\mathrm{mm}$ from the $\mathrm{OG}$ and which can easily be observed after desheathing of the nerve in unstained preparations. These 2 cell bodies, which appear equivalent in morphology and function, are subsequently referred to as the PS neurons and are characterized on the following basis. Cobalt backfills of nerve tracts to the OG show that the 2 neurons have identical axonal geometries with branches in the superior esophageal nerves (sons; Fig. $2 A$ ), the inferior esophageal nerves (ions; Fig. $2 B$ ), and the stomatogastric nerve (stn; Fig. $2 C$ ). This geometry, which is schematized in Figure $3 A$, was confirmed electrophysiologically with simultaneous recordings from the cell body of a PS neuron and the right and left sons $\left(\right.$ son $_{\mathrm{r}}$, son $\mathrm{s}_{i}$; Fig. $\left.3 B_{l}\right)$ and of the stn (Fig. $3 B_{2}$ ). Conversely, electrical stimulation of either the stn
(Fig. $3 C_{1}$ ) or an son (Fig. $3 C_{2}$ ) induces antidromic spikes 1:1 and at constant latency in the penetrated cell body of PS. Although injection of Lucifer yellow into a PS cell body has confirmed that these neurons project into the ion, it has never been possible either to observe ion spikes correlated with PS soma potentials or to induce soma spikes antidromically by stimulation of the ion. In all the experiments in which a cell body located in the ivn was penetrated, its identification as a PS neuron was therefore demonstrated initially by stimulation of the stn and son to obtain an antidromic spike in the impaled soma. A second phenomenon that characterizes the PS neurons is their excitatory effects, apparently monosynaptic, on all pyloric dilator neurons in the STG. This is evident in Figure $3 D$, where spikes evoked in PS by intrasomatic current injection or by axonal stimulation (see below) are followed 1:1 by EPSPs in $\mathrm{PD}$ (Fig. $3 D_{1}$ ), $\mathrm{AB}$ (Fig. $3 D_{2}$ ), and VD (Fig. $3 D_{3}$ ). The third and most spectacular characteristic of a PS neuron resides in the ability of its discharge to abolish the oscillatory activity of sev- 
A

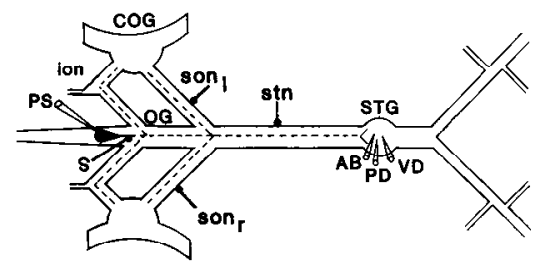

$B_{1}$

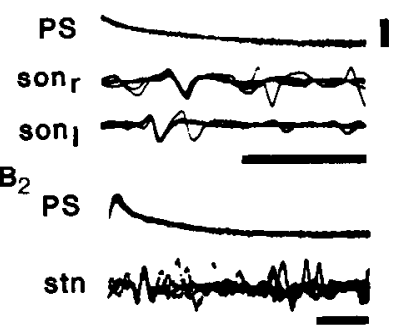

$D_{1}$

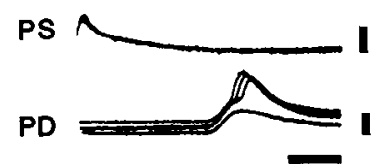

antidromic stimulation

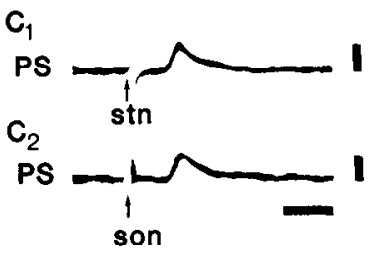

$\mathrm{D}_{2}$

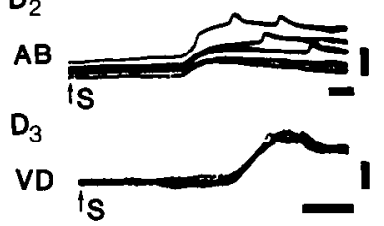

Figure 3. Electrophysiological characterization of a PS neuron. $A$, Diagram of the experimental preparation showing the position of electrodes for intra/extracellular recording and stimulation of PS and intracellular recording from postsynaptic pyloric neurons in the STG. Note that the axon of PS was also stimulated via an extracellular electrode $(S)$ placed on the ivn between the cell body and the $O G$. $B$, Superimposed oscilloscope sweeps (4) triggered by PS intrasomatic spikes. Each action potential in the cell body is followed at constant latency by an impulse in the left (son) and right (son $)$ superior esophageal nerves $\left(B_{i}\right)$ and the $\sin \left(B_{2}\right)$. $C$, Stimulation (arrows) of the $\operatorname{stn}\left(C_{1}\right)$ and the $\operatorname{son}\left(C_{2}\right)$ elicits an antidromic spike (5 sweeps) in the PS cell body. $D$, PS neuron evokes a large, constant-latency EPSP in pyloric dilator neurons $(P D)(D),, A B$ $\left(D_{2}\right)$, and $V D\left(D_{3}\right)$. In $D_{t}$, PS was activated by intrasomatic injection of depolarizing current, and in $D_{2}$ and $D_{3}$, by extracellular stimulation of its axon $(S$, in $A)$. Each panel consists of 5 superimposed oscilloscope sweeps. $B_{2}$ and $D_{1}$ are from Cazalets et al. (1987b). Horizontal scale bars, $10 \mathrm{msec}$; vertical scale bars, $10 \mathrm{mV}$.

eral pyloric neurons, including PD and LP, as shown in Figure $4 A$.

Important to note is that all cell bodies penetrated in the proximal part of the ivn satisfied the above 3 criteria, thus indicating that the PS somata alone are located in this region of the stomatogastric nervous system.

Routine long-term recordings from the cell bodies of PS neurons are difficult to obtain. When not penetrated, however, PS neurons can still be activated by extracellular stimulation of their axons in the proximal ivn (Fig. $3 A$ ). That such procedures produce the same effects on pyloric neurons as induction of PS firing by intrasomatic current injection is shown in Figure $4 B$. In this experiment, tonic stimulation $(8 \mathrm{~Hz})$ of the proximal part of the ivn abolishes PD and LP oscillations ( $\mathrm{Fig} .4 B_{2}$ ) that otherwise occurred spontaneously (Fig. $4 B_{1}$, cf. with Fig. $4, A_{2}$, $A_{l}$, respectively). These effects were not due to activation of other fibers in the ivn, because identical stimulation of the distal ivn (i.e., with an electrode placed between PS cell bodies and the brain) never had any effect on pyloric network activity.

The only obvious difference between intracellular stimulation

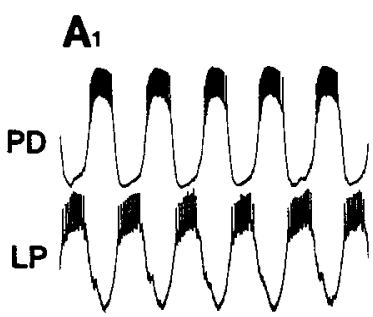

$A_{2}$

PS

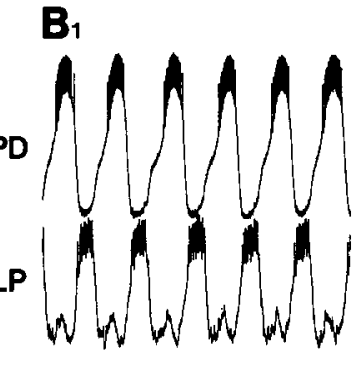

$\mathbf{B}_{2}$
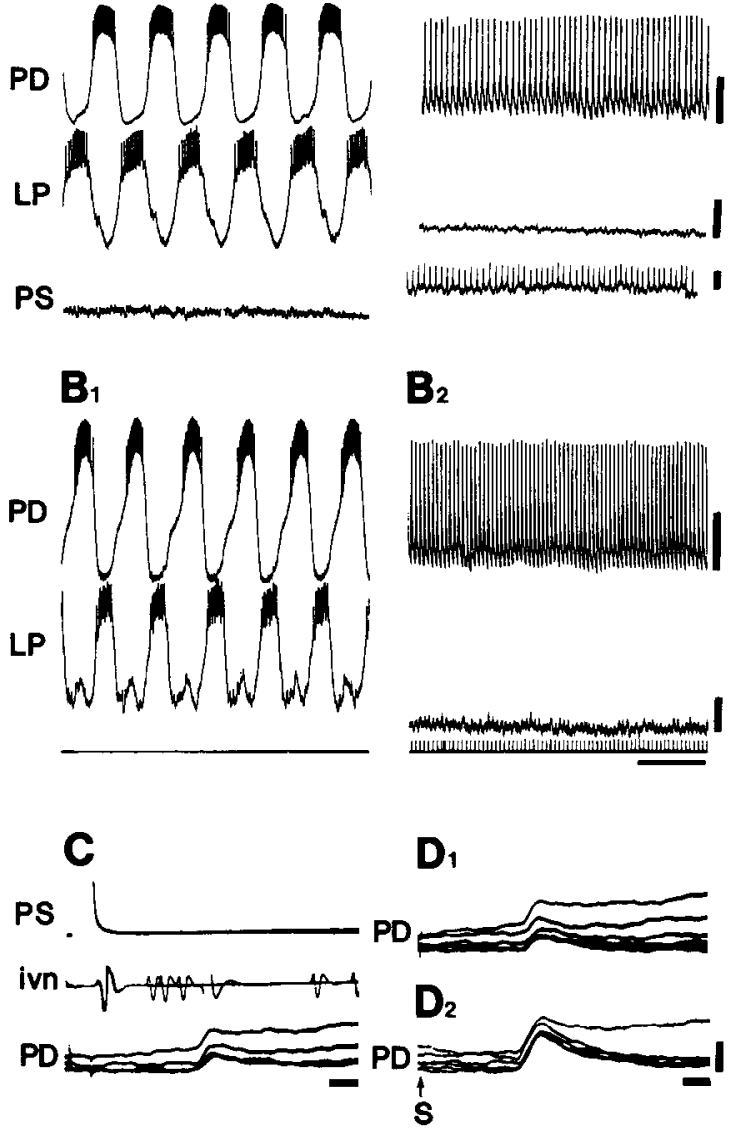

Figure 4. Comparison of the effects on pyloric neurons of intracellular stimulation of a PS neuron and extracellular stimulation of the proximal ivn ( $S$ in Fig. $3 A$ ). $A$, Injection of depolarizing current into a previously silent $\left(A_{l}\right)$ cell body of PS causes it to fire tonically at $7 \mathrm{~Hz}\left(A_{2}\right)$. The PD and LP neurons in the STG cease to oscillate (cf. $A_{2}, A_{l}$ ); PD fires tonically and LP becomes silent. $B$, Stimulation of the proximal ivn at $7 \mathrm{~Hz}$ produces the same effects $\left(B_{2}\right)$ on $\mathrm{PD}$ and LP neurons that were previously oscillating $\left(B_{1}\right)$ (compare $A$, with $B_{1}$ and $A$, with $B_{2}$ ). $C$, PS action potentials recorded in the cell body (4 oscilloscope sweeps) are followed $1: 1$ and at a constant latency by action potentials in the proximal ivn and small EPSPs in PD. $D$, Stimulation of the proximal ivn $(S)$ at low voltage $\left(D_{l}\right)$ produces an EPSP of similar amplitude in $C$. An increase in stimulus voltage $\left(D_{2}\right)$ evokes a larger EPSP that remains constant with further increase in stimulus intensity (see text). Horizontal scale bars: $2 \mathrm{sec}, A, B ; 10 \mathrm{~ms}, C, D$; vertical scale bars: $10 \mathrm{mV}, A, B$; $5 \mathrm{mv}, C, D$.

of a PS cell body and extracellular stimulation of the proximal ivn is that the latter can induce simultaneous firing of both PS neurons. In Figure $4 C$, for example, the firing of 1 PS neuron is provoked by intracellular depolarization, and a small amplitude EPSP in PD corresponds to each spike (also recorded in the proximal ivn). Stimulation of the proximal ivn (Fig. $4 D$ ) causes a similar small-amplitude EPSP in PD (Fig. $4 D_{\imath}$ ) as long as the stimulus intensity remains low. Increasing the intensity of stimulation results suddenly in a PD EPSP that is almost twice as large (Fig. $4 D_{2}$ ) and whose amplitude cannot be modified by a further increase in stimulus strength. This indicates that in the latter situation (Fig. $4 D_{2}$ ) the 2 PS axons are recruited together, thereby producing a summated EPSP in PD, while in the former situation (Fig. $4 D_{l}$ ) only 1 PS axon was being activated, as with direct intracellular stimulation (Fig. 4C). In all experiments in which stimulation of the proximal ivn was used 


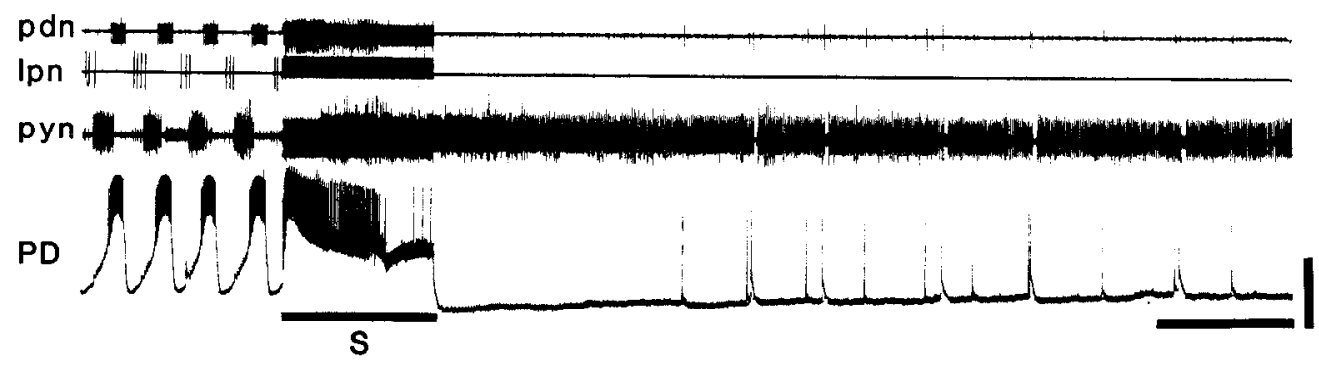

Figure 5. Discharge of the PS neurons can induce a complete and long-lasting cessation of pyloric rhythmicity. The PS cells were stimulated extracellularly (bar) in the proximal ivn. Pyloric rhythmic activity was recorded extracellularly from the terminal motor nerves containing the axons of PD, LP, and PY, respectively, and from the soma of the pacemaker PD. The stimulation ( 6 sec at $30 \mathrm{~Hz})$ provoked.a strong depolarization of PD, followed by a complete cessation of rhythmic pyloric activity that outlasts the PS discharge by several $10 \mathrm{~s}$ of seconds (traces are until $t=$ $30 \mathrm{sec}$ only). Horizontal scale bar, $5 \mathrm{sec}$; vertical scale bar, $15 \mathrm{mV}$.

to activate PS, the stimulus strength was set at a level that induced firing of both PS cells.

\section{Long-lasting effects of PS neurons on the pyloric pattern}

In the previous section it was shown that tonic discharge of PS causes cessation of rhythmic (cycling) activity in PD and LP neurons (Fig. 4, $A, B$ ). A further dramatic characteristic of this effect is its long duration. This is shown in the experiment of Figure 5 in which a brief $(6 \mathrm{sec})$, high-frequency $(30 \mathrm{~Hz})$ discharge of PS induced by stimulation of the cells' axons provoked a complete cessation of cyclic activity in PD and LP (see recordings from the pyloric dilator nerve, pdn, and from the lateral pyloric nerve, lpn, for more than $40 \mathrm{sec}$ after the end of the stimulation). These long-term effects also impinge on the PY neurons (see recording from the pylonic nerve, pyn), which no longer burst after PS discharge but fire tonically at high frequency. In other words, the 3 classes of neurons that drive the pyloric filter (i.e., the pacemakers $P D-A B$ as well as the constrictors LP and PY) are affected long-lastingly, remaining either silent or tonically active by a brief PS discharge.

This long-duration effect is further evident from simultaneous intracellular recordings of the 3 classes of pyloric neuron as shown in Figure $6 \mathrm{~A}$. Here a brief discharge of a PS neuron induced by intrasomatic depolarizing current injection results in a cessation of oscillatory activity in all 3 cell types followed by a slow recovery of their bursting. The temporal characteristics
Figure 6. PS neuron discharge can induce long-lasting modifications in the period of the pyloric rhythm. $A$, In a spontaneously oscillating preparation, PS discharge ( $5 \mathrm{sec}$ at $30 \mathrm{~Hz}$ ), elicited by an intrasomatic depolarizing current pulse (bridge circuit unbalanced), provoked: (1) a depolarization of the PD neuron during PS discharge and a subsequent long-lasting decrease in oscillation frequency, (2) an immediate longlasting inactivation of LP, and (3) a long-lasting depolarization of the PY neuron that discharged tonically. $B$, Time course of the oscillatory period of the pacemaker PD after PS discharge ( 5 trials, each with PS firing for $5 \mathrm{sec}$ at $25 \mathrm{~Hz}$ ). Each point is the mean period value during a 5-sec bin. In this experiment, the mean cycle period was 1.31 $\sec (\mathrm{SEM}= \pm 0.024 ; n=28$ ) before PS stimulation. PS discharge (arrow) was followed by a 15 -sec pause in $\mathrm{PD}$, which then recommenced much slower bursting and a gradual recovery toward control values. At $80 \mathrm{sec}$ after PS discharge the pyloric period $(1.49 \mathrm{sec}$; SEM = $\pm 0.067 ; n=18$ ) was still significantly different ( $p=3.10^{-4}$; student's $t$ test) from the control period. Error bars are SEM. Horizontal scale bar, 5 sec; vertical scale bars, $10 \mathrm{mV}$.

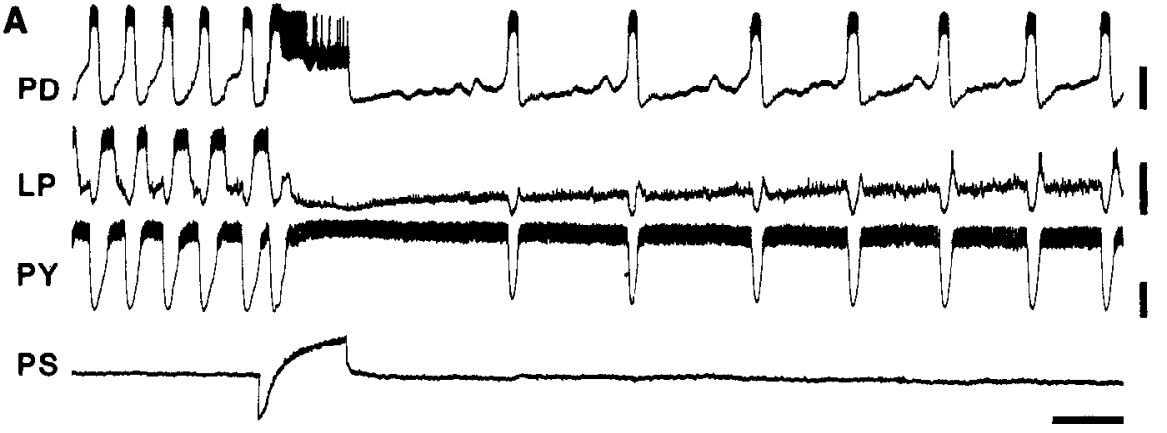

B

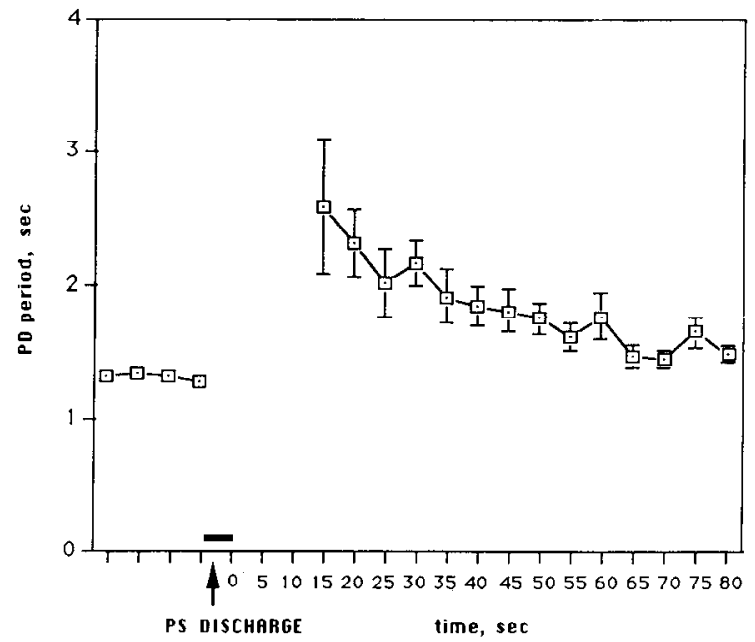




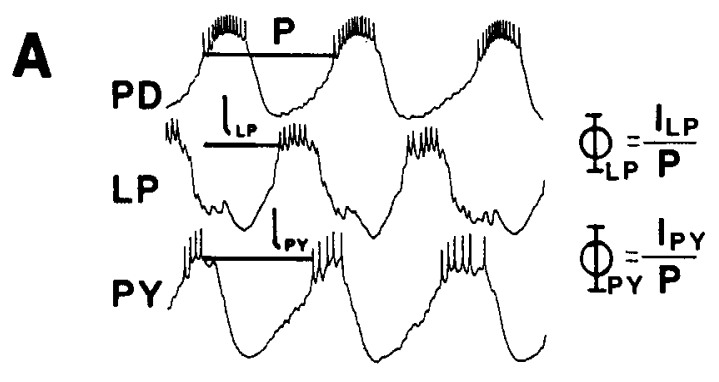

B
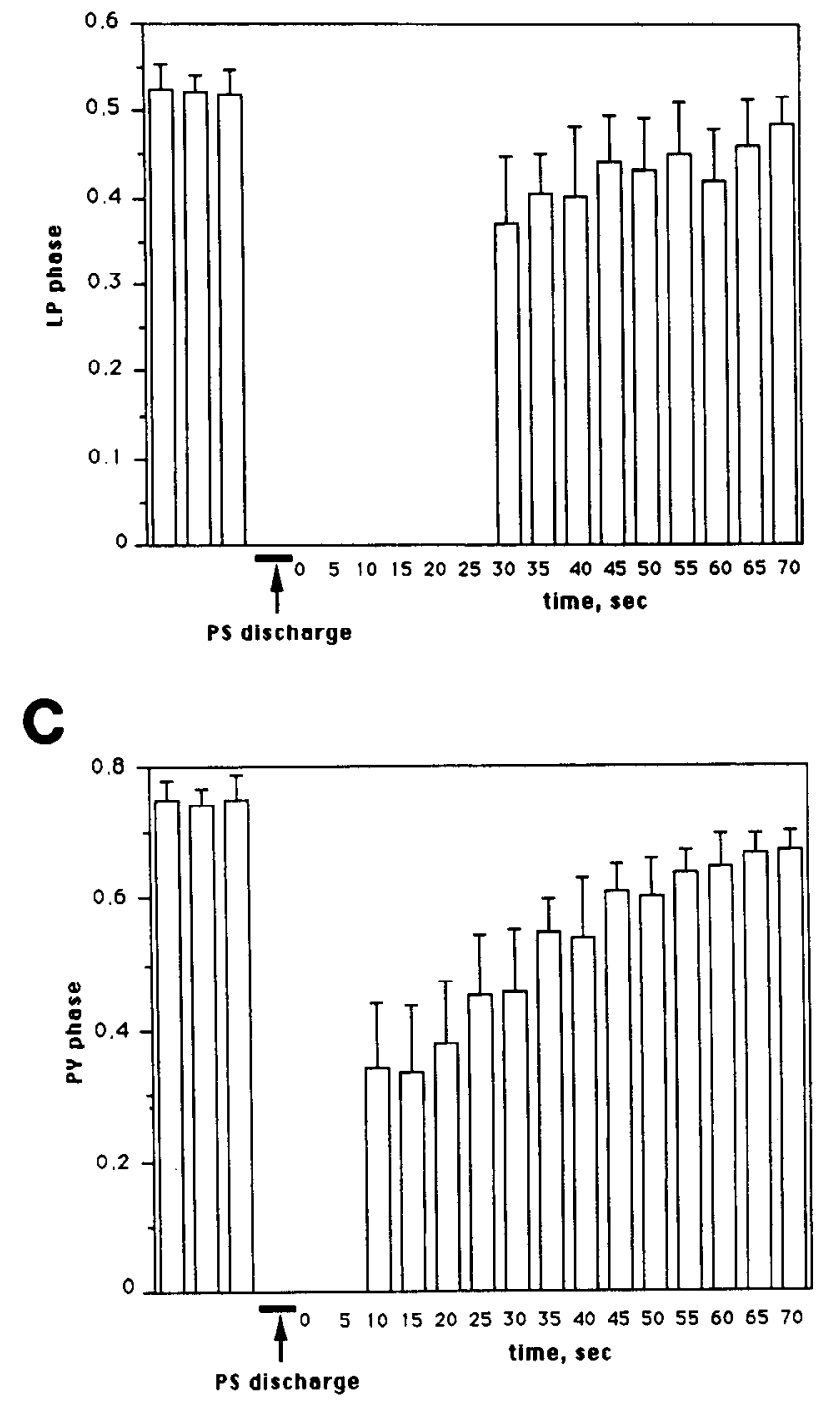

Figure 7. PS neuron discharge induces long-lasting modifications in the phase relationships between pyloric neurons. $A$, Phase of constrictor $(L P, P Y)$ burst activity in the pacemaker $P D$ cycle is calculated from the ratio between the latency $(I)$ to burst onset and the period $(P)$. Data from the same experiment as in Figure $6 B . B, C$, PS discharge $(5 \mathrm{sec}$, $25 \mathrm{~Hz}$ ), clicitcd by intrasomatic injection of depolarizing current, caused a marked reduction in the phase values of both constrictor neurons. When LP neuron recommenced bursting after PS discharge, its phase had shifted from 0.52 to $0.37(B)$. Similarly for PY whose phase value decreased from 0.75 to $0.34(C)$. In both cases the PS-evoked changes in phase were long-lasting, remaining significantly different from control values even at $70 \mathrm{sec}$ after the original PS discharge (for further details see text). Each histogram panel represents pooled measurements from 5 successive trials in the same experiment, while individual columns are mean phase values $( \pm \mathrm{SD})$ within 5 -sec bins.

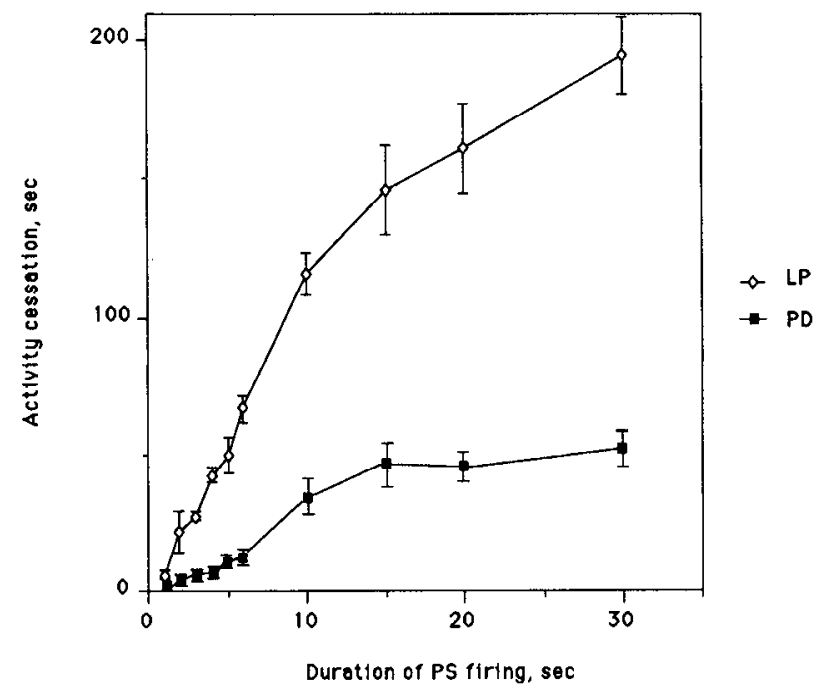

Figure 8. Cessation of PD and LP bursting is dependent on the duration of PS discharge. PS discharge $(25 \mathrm{~Hz})$ was elicited by intrasomatic depolarizations of increasing duration. For a given neuron $(L P$ or $P D)$, each point represents the mean inactivation time $( \pm S D)$ measured from 5 trials in the same experiment. Recovery of bursting activity in both cells was progressively delayed with increasing duration of PS discharge, with LP displaying a greater sensitivity than PD. Note that the duration of PD inactivation reaches a plateau at a PS discharge time of $15 \mathrm{sec}$, while LP inactivation continues to grade with PS discharge up to 30 sec.

of these long-term effects on the pyloric pattern are presented in Figure $6 B$, where the cycle period of PD before and after repeated brief PS discharges in a single experiment was measured and plotted against pre- and poststimulus time. PS discharge provokes a cessation of the cycling pattern (more than $12 \mathrm{sec}$ for a $5 \mathrm{sec}$ of PS firing at $25 \mathrm{~Hz}$ ), followed by a recovery time during which the cycle period of PD is initially long and variable, then slowly decreases, and becomes progressively more regular. Even after $80 \mathrm{sec}$, however, PD oscillation period $(M$ $=1.49 \mathrm{sec} ; \mathrm{SEM}= \pm 0.067, n=18)$ is still significantly different ( $p=3.10^{-4}$; Student's $t$ test) from prestimulus control values $(M=1.31 \mathrm{sec} ; \mathrm{SEM}= \pm 0.024, n=28)$.

In addition to altering the occurrence of the pyloric rhythm, PS activity can produce long-duration modifications in the structure of the pyloric motor pattern (Fig. 7). This is evident from observations on 2 parameters of the pattern: (1) the number of neurons that participate in the pyloric rhythm, and (2) the phasing of bursts in the LP and PY neurons in the cycle of the pacemaker PDs (Fig. 7A). Both these parameters were strongly and long-lastingly modified by 5 -sec $(25 \mathrm{~Hz})$ test discharges in PS. Throughout a $25-\mathrm{sec}$ poststimulus period (i.e., from $\mathrm{t} 5 \mathrm{sec}$, where PD begins to burst again, until t30 sec, where LP recovers bursting; compare Fig. $7 B$ with Fig. $7 C$ ), the rhythm consisted of alternating discharge in PD and PY neurons only. During this time, therefore, the action of PS resulted in a switch from a triphasic to a biphasic pattern. Considerable and long-lasting changes in phase relationships also occurred, with bursts in both constrictor neurons (LP and PY) becoming phase-advanced in the dilator cycle. Whereas the phase of LP bursts in PD time was $0.52(\mathrm{SD}= \pm 0.023, n=52)$ before PS discharge, it was shifted to 0.37 ( $\mathrm{SD}= \pm 0.076, n=6$ ) when $\mathrm{LP}$ recovered bursting after PS discharge (Fig. 7B). LP phase then slowly returned to its original value, but was still significantly different $\left(p<10^{-4}\right.$; Student's $t$ test) at $70 \mathrm{sec}$ after the end of PS discharge. The 
Figure 9. Progressive reconfiguration of the pyloric network by the PS neuron: Each panel shows recordings of the 3 neurons $(P D, L P, P Y)$ that control movements of the pyloric filter, during different frequencies of tonic PS discharge (induced by extracellular stimulation of its axon in the ivn; note the large PS-derived EPSPs in the PD recording). Bar diagram at the bottom of each panel shows the mean $( \pm$ SEM) phase positions of activity in the 3 cells over 30 duty cycles. $A$, Control rhythmicity in the absence of PS firing. $B$ $D$, Increasing frequencies of discharge in PS $(5,6,7 \mathrm{~Hz})$ provokes a progressive decrease in the activity of the LP neuron $(B, C)$ until the neuron falls silent $(D)$. Gradual changes in the activity of the PD and PY neurons can also be observed. Thus a small increase in PS spike frequency causes a shift from a triphasic pyloric pattern $(B, C)$ to a biphasic pattern $(D)$, consisting of alternate bursts in PD and PY alone. Horizontal scale bar, I sec; vertical scale bar, $10 \mathrm{mV}$.
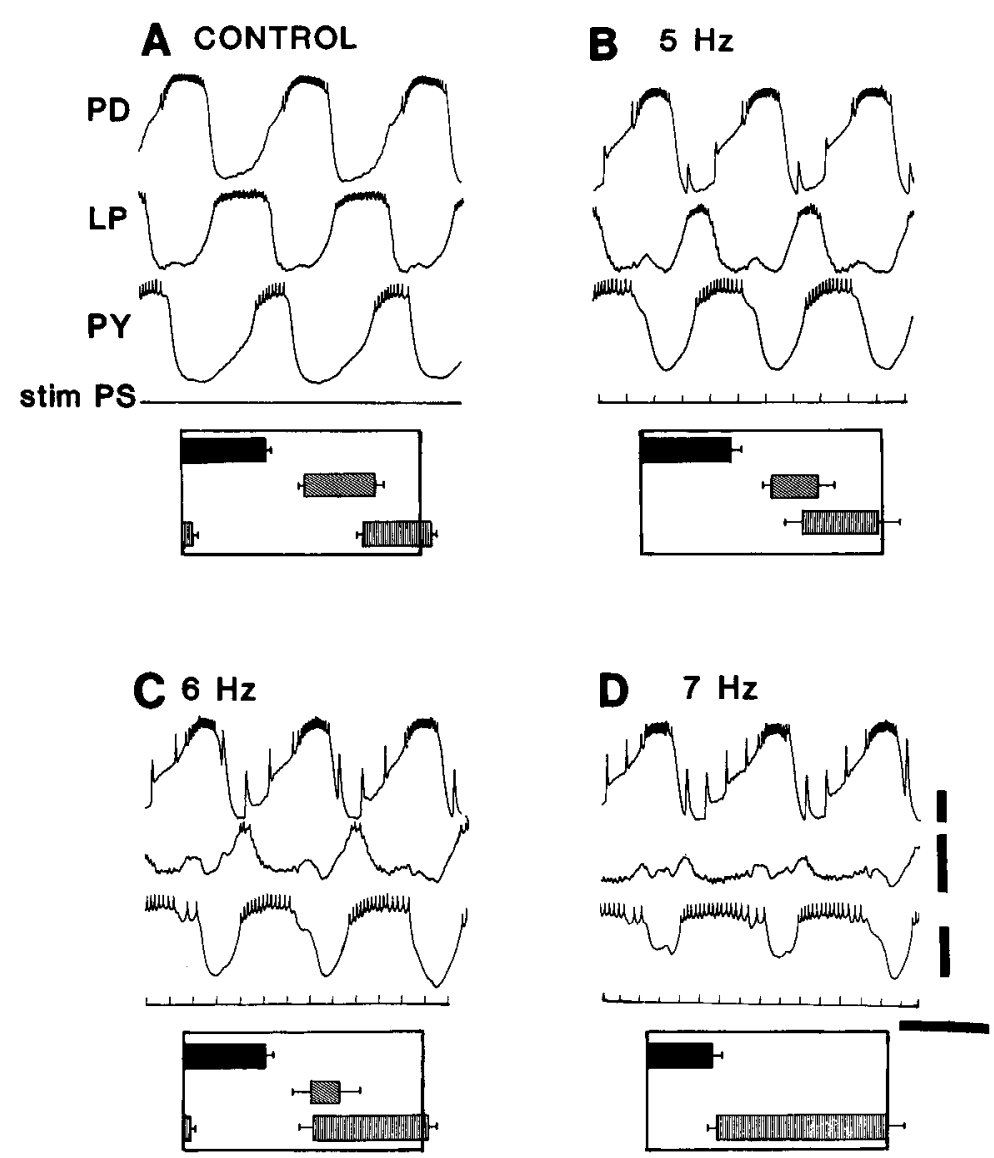

phase of the PY bursts in the PD period also became advanced, shifting from 0.75 (SD $= \pm 0.03, n=53$ ) before PS firing to $0.34(\mathrm{SD}= \pm 0.09, n=13)$ when PD oscillations recovered. It too slowly increased in value, but was still significantly different from its original value ( $p<10^{-4}$; Student's $t$ test) at $70 \mathrm{sec}$ after PS discharge (Fig. $7 C$ ). These phase shifts were due not only to the considerable increase in the period of the pyloric rhythm after PS activity (Fig. $6 B$ ), but also to a substantial decrease in the latency to onset of firing of the constrictor neurons in each PD cycle.

In summary, therefore, a phasic discharge of PS can produce complete suppression of rhythmic activity which considerably outlasts the cell's discharge and which is followed by a strong modification in the structure of the pyloric pattern that may last 10-20 times longer than the original PS activity.

Finally, the duration of the effects of PS on pyloric neurons is dependent on the duration of discharge in PS itself. This is illustrated in Figure 8, where the interval of burst cessation in PD and LP neurons is plotted against the duration of PS firing at $25 \mathrm{~Hz}$. Successive trials during the same experiment showed that increasing the firing time of PS prolongs the subsequent cessation of bursting in both PD and LP. For PD, however, this effect reaches maximum duration with about $15 \mathrm{sec}$ of PS firing, while suppression of bursting in LP continues to grade up to PS firing durations of $30 \mathrm{sec}$. Effect of longer stimulations of PS has not been tested owing to adaptation of the cell to such longduration stimulations at $25 \mathrm{~Hz}$. Moreover, there is a large difference in sensitivity of the 2 neurons to the PS discharge, as evident from the slopes of the 2 curves. For example, a $15-\mathrm{sec}$ discharge of PS abolishes LP bursting for $150 \mathrm{sec}$ while PD remains silent for $45 \mathrm{sec}$ only.

\section{Functional reconfiguration of the pyloric network induced by tonic PS discharge}

One of our initial criteria for characterizing a PS neuron was the ability of sustained tonic discharge to abolish oscillatory bursting activity in PD and LP (e.g., Fig. 4, $A, B$ ). As such a suppressive effect is observed with PS firing frequencies higher than $10 \mathrm{~Hz}$, a question remaining is whether lower-discharge intensities in PS, although insufficient to suppress the pyloric rhythm, are nonetheless capable of modifying the pyloric pattern. The effects of a tonic discharge in PS at 5,6 , and $7 \mathrm{~Hz}$ are examined in Figure 9, $B-D$, respectively, with each panel containing the phase diagram of the corresponding pyloric pattern as measured from 30 cycles. With the exception of the PD pacemaker period, which remained constant at low PS discharge frequencies, all other parameters of activity were graded and significantly modified with minimal $(1 \mathrm{~Hz})$ increases in PS frequency. Again, LP appeared to be the most sensitive neuron to PS discharge: even at PS frequencies as low as $5 \mathrm{~Hz}$, the LP burst duration was $50 \%$ less than that of the control pattern. As the frequency of PS increased to $6 \mathrm{~Hz}$, the duration of LP bursts diminished even further (Fig. 9C) until the neuron fell completely silent at $7 \mathrm{~Hz}$ (Fig. 9D). At the same time, PS activity also gradually modified PD and PY activity. Between 0 and 7 $\mathrm{Hz}$ in PS, the duration of PD bursts was diminished by about $20 \%$ and the mean frequency of PD spikes during bursts was diminished from 100 to $70 \mathrm{~Hz}$. By contrast, the duration of PY bursts became lengthened, they started earlier in the PD cycle, and they contained progressively more impulses.

An important point to stress here is the extreme sensitivity of the pyloric network to changes in PS firing; in the represen- 


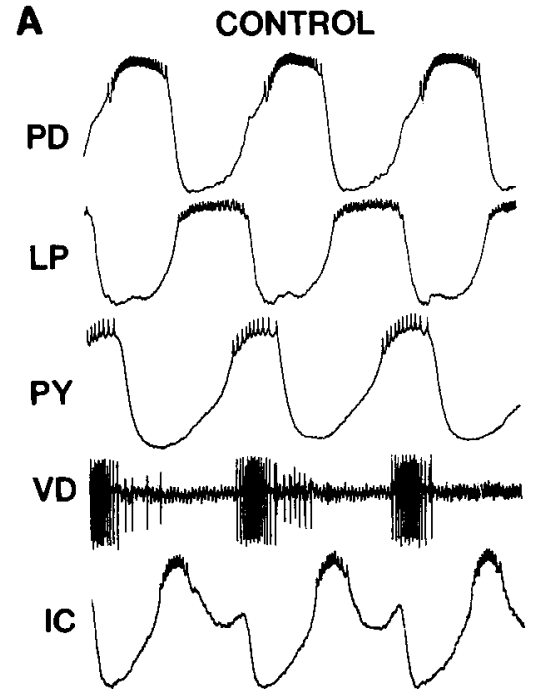

B
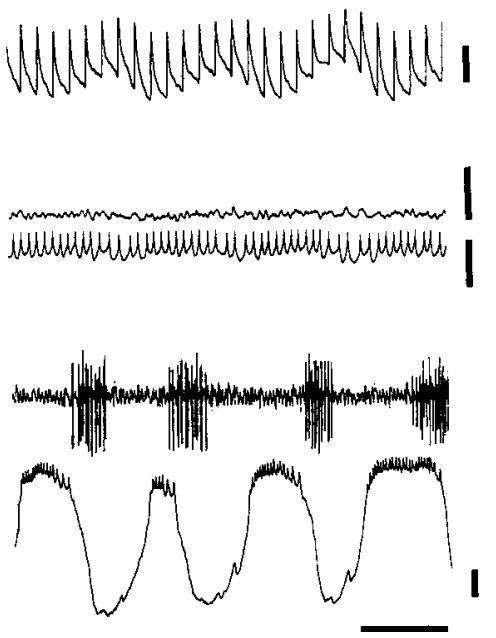

Figure 10. Functional reconfiguration of the pyloric network by the PS neuron: elimination of neurons of the pyloric filter. In this experiment (same as Fig. 9) all 5 types of motoneuron implicated in the pyloric motor pattern were recorded simultaneously with the VD neuron monitored by extracellular recording from its motor nerve ( $m v n$, Fig. $1 B$ ). $A$, Control rhythmicity. $B$, PS stimulation $(12 \mathrm{~Hz})$ produced a cessation of rhythmic behavior in the 3 neurons (including pacemaker PD) that drive the pyloric filter, but pyloric valve neurons, $V D$ and $I C$, continued to oscillate and kept in approximate antiphase. Horizontal scale bar, $0.5 \mathrm{sec}$; vertical scale bar, $10 \mathrm{mV}$. tative example of Figure 9, an increase from only $3 \mathrm{~Hz}$ (onset of observable PS effects, not shown) to $7 \mathrm{~Hz}$ (Fig. 9D) was sufficient to provoke a functional switch from a triphasic to a biphasic pyloric pattern (by selectively silencing LP) and to induce substantial modifications in the phase of PY neuron activity. Thus, the action of PS appears not simply to provoke a complete cessation of the pyloric rhythmicity, but at low $(<10$ $\mathrm{Hz}$ ) discharge frequencies, it has the capability to finely control the structure of the pyloric motor pattern, in terms of both the phase relations between pyloric neurons and their individual discharge characteristics.

In contrast to pyloric filter neurons, the 2 cells ( $V D$ and $I C$, Fig. 10A) that control the pyloric valve (see Fig. 1) are relatively insensitive to the effects of PS. As seen in Figure $10 B$ where PS was stimulated at $12 \mathrm{~Hz}$, a complete cessation of rhythmic activity in neurons (PD, LP, PY) controlling the pyloric filter was observed, although the VD and IC neurons continued to be rhythmically active. Thus, whereas under control conditions the VD and IC neurons were controlled by the discharge of the pacemaker dilator neurons, during PS discharge they were free to oscillate independently at an intrinsic frequency higher than before. This sustained oscillatory activity was not due to rhythmic synaptic inhibition from the $\mathrm{AB}$ neuron, since this neuron also ceases to oscillate during PS stimulation (this absence of $A B$ rhythmic firing is evident in Fig. $10 B$ from the lack of any ABderived rhythmic inhibition of the LP and PY neurons; see also Cazalets et al., 1990). From a functional point of view, therefore, PS activity appears to be able to dissect the pyloric network and separate the elements that govern the pyloric filter (which fall silent) from those controlling the pyloric valve (which remain rhythmically active).

Figure 11 summarizes the effects of PS on the pyloric $\mathrm{CPG}$ in terms of functional reconfiguration of the network. The diagrams represent 3 different functional states of the pyloric nctwork as observed in the present study. Figure $11 \mathrm{~A}$ is the complete circuit where all elements are spontaneously active and PS remains silent. At a PS frequency discharge of $7 \mathrm{~Hz}$, the LP neuron ceases to oscillate and fire and therefore no longer participates in the functional network. A small increase of the PS discharge frequency (to ca. $12 \mathrm{~Hz}$ ) provokes a transition to a third state, where the functional network consists only of the 2 neurons controlling the pyloric valve. Important to note is that Figure $11, B$ and $C$, represent states that are only points on a progression of change (e.g., in phasing, burst duration, and intensity) that gradually shifts the network from one configuration to another. Noteworthy also is that while the absolute frequencies of PS discharge at which different functional states could be obtained varied from one experiment to another, the differences were relatively small and were always within the same order of magnitude.

\section{Discussion}

Our goal in this study was to characterize how a pair of newly identified neuromodulatory neurons, the PS neurons, can act on a CPG to modify its ongoing activity in vitro. As discussed below, we have found that the discharge of these neurons can affect most parameters of the PY motor output.

\section{Suppressive action}

The major feature of the effects of PS is its suppression of rhythmic pyloric activity. All previously described inputs to CPGs exert a permissive, activating form of modulation; i.e., they initiate or enhance rhythmic activity in their target networks (Harris-Warrick, 1988).

Several activating inputs to the pyloric CPG have been identified electrophysiologically and appear to act via neurotransmitters such as acetylcholine (Nagy and Dickinson, 1983), serotonin (Katz and Harris-Warrick, 1987), and proctolin (Nusbaum and Marder, 1987). In addition, bath application of putative neurotransmitters and/or their agonists has indicated that the pyloric network may be the target of numerous input substances, including amines (dopamine, serotonin, octopamine; Raper, 1979; Beltz et al., 1984; Marder and Eisen, 1984; Flamm and Harris-Warrick, 1986a, b), peptides (proctolin, FMRFamide, substance P; Hooper and Marder, 1984, 1987; Marder et al., 1986, 1987; Marder, 1987), and acetylcholine (Marder and Eisen, 1984; Nagy et al., 1985). Moreover, Claiborne and Selverston (1984b) have reported that iontophoretic application of histamine was able to provoke a hyperpolarization of the PD 
Figure 11. Diagramatic representation of the different functional pyloric networks induced by PS discharge. Dashed circles and lines show ncurons and their synaptic connections that no longer participate in the pyloric pattern when the PS neurons fire.

A CONTROL

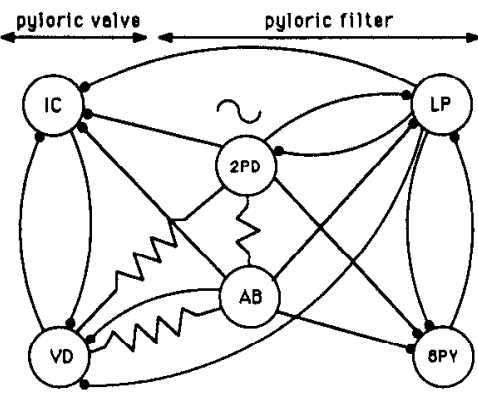

\section{B PS DISCHARGE $7 \mathrm{~Hz}$}

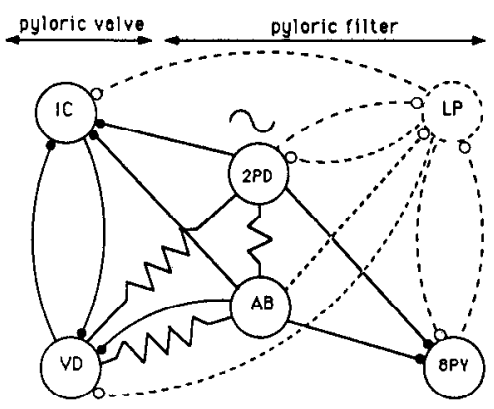

C PS DISCHARGE $12 \mathrm{~Hz}$

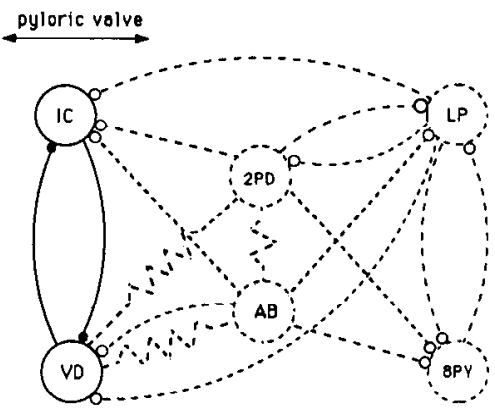

neurons, but with no detectable effects on other pyloric neurons. They have shown that 2 neurons projecting to the STG, the ivnthrough fibers (ivn-TF), contain histamine. The action of the ivn-TFs on the pyloric neurons is complex as they evoke a biphasic response (mixed EPSP and IPSP) in the dilator pacemakers: at low ivn-TF frequency the excitatory response predominates, but gives way to the inhibitory response at high discharge frequency (Sigvardt and Mulloney, 1982; Claiborne and Selverston, 1984a, b). Moreover, ivn-TF evokes a longlasting enhancement of the bursting properties of the pyloric pacemakers (Russell and Hartline, 1981).

In contrast to the above studies, our results reported here directly confirm the idea that neuronal inputs can effectively control the rhythmic activity of a CPG in a suppressive way. Thus, it appears that CPG may in fact be subject to a dualcontrol mechanism, involving, on one hand, activating pathways, which stimulate rhythmic activity in a relatively quiescent preparation, and, on the other hand, suppressive pathways which diminish this rhythmic activity. Moreover, it is possible that these opposing inputs sometimes operate in a more drastic manner by completely turning on, or off, the activity of the CPG. Cessations or decreases in pyloric activity have been observed in vivo (Rezer and Moulins, 1983) and could result not only from a diminution of activating influences, but also from the involvement of suppressive pathways. Moreover, GABA applied exogenously in vitro has recently been shown to suppress pyloric activity (Cazalets et al., 1987a). As numerous neuromodulatory inputs to the pyloric network seem to exist, we can suppose that among them there is a variety of inactivating pathways, acting on different neurons, or at different times. This type of neuromodulation has not been previously described, probably because most isolated preparations studied to date tend to be in a quiescent state, and the effort therefore has been devoted to the search for activating pathways.

\section{Mode of discharge of the PS neuron}

Another prominent feature of the influence of PS on the pyloric network is the duration of its effect, which can be 20 times longer than the cell's own discharge. Following a brief, highfrequency discharge of PS, the period, the number of neurons participating in a given rhythmic activity, and the phase relationships between the pyloric neurons are greatly modified (Figs. 6 and 7). However, even when tonically active at low frequencies, PS produces considerable modifications in the pyloric output (Figs. 9 and 10). Although it is not known whether PS activity in vivo is phasic or tonic, it is possible that both discharge modes are utilized, as is sometimes seen to occur spontaneously in vitro (unpublished observations). This would therefore maximize the range of effects that PS could have on the activity of the pyloric network; a brief PS discharge would provoke temporary modifications (lasting 10 s of seconds) in the activity of the pyloric network, while a tonic discharge would freeze the pyloric network in a given configuration that is PS-frequency dependent and is maintained for as long as PS is active.

In this context, the mode of discharge of a neuromodulatory neuron would also determine the type of modulation occurring and in turn represents a further substrate for optimal tuning of a network by neuromodulatory inputs.

\section{"Instructive" action}

We have suggested in the first part of this discussion that 2 functionally antagonistic systems, acting in an all-or-none manner, could suppress or initiate the activity of a CPG. In fact, this is not the only mode of action, for either suppressive or permissive inputs. The PS neuron, for example, can exert extremely subtle control over the pyloric rhythm, including variations in the rhythm period (Fig. 6), the phase relationships between the different neurons (Fig. 7), and the duration of bursts 
and the spike frequency within each burst (Fig. 8). Moreover, PS activity not only modifies most parameters of ongoing activity in an already functional network, but the cell's firing can also lead to a restructuring of the active pyloric circuit. This is achieved by the progressive and selective elimination of elements participating in the network (Figs. 9-11). On this basis, the complete anatomical diagram of the network represents a templatc from which modulatory inputs can select multiple configurations of the active pyloric circuit, allowing optimal adaptation to all biological contingencies. This notion of neuromodulation of pyloric activity has already been advanced on the basis of pharmacological studies (Flamm and Harris-Warrick, 1986a, b; Harris-Warrick, 1988), from which these authors proposed that different amines could define different pyloric circuits. Our results show that stimulation of a single identified neuron can also redefine the active pyloric circuit.

\section{References}

Bal, T., F. Nagy, and M. Moulins (1988) The pyloric central pattern generator in crustacea: A set of conditional neuronal oscillators. $J$. Comp. Physiol. A 163: 715-727.

Beltz, B., J. S. Eisen, R. Flamm, R. M. Harris-Warrick, S. L. Hooper, and E. Marder (1984) Serotonergic innervation and modulation of the stomatogastric ganglion of three decapod crustaceans (Panulirus interruptus, Homarus americanus and Cancer irroratus). J. Exp. Biol. 109: 35-54.

Cazalets, J. R., I. Cournil, M. Geffard, and M. Moulins (1987a) Suppression of oscillatory activity in crustacean pyloric neurons: Implication of GABAergic inputs. J. Neurosci. 7: 2884-2893.

Cazalets, J. R., F. Nagy, and M. Moulins (1987b) Suppressive control of a rhythmic central pattern generator by an identified modulatory neuron in crustacea. Neurosci. Lett. 81: 267-272.

Cazalets, J. R., F. Nagy, and M. Moulins (1990) Suppressive control of the crustacean pyloric network by a pair of identified interneurons. II. Modulation of neuronal properties. J. Neurosci. 10: 458-468.

Claiborne, B. J., and A. I. Selverston (1984a) Localization of stomatogastric IV neuron cell bodies in lobster brain. J. Comp. Physiol. A 154:27-32.

Claiborne, B. J., and A. I. Selverston (1984b) Histamine as a neurotransmitter in the stomatogastric nervous system of the spiny lobster J. Neurosci. 4: 708-721.

Dickinson, P. S., and F. Nagy (1983) Control of a ecntral pattern generator by an identified modulatory interneurone in Crustacea. II. Induction and modification of plateau properties in pyloric neurones. J. Exp. Biol. 105: 59-82.

Flamm, R. E., and R. M. Harris-Warrick (1986a) Aminergic modulation in lobster stomatogastric ganglion. I. Effects on motor pattern and activity of neurons within the pyloric circuit. J. Neurophysiol 55: $847-865$.

Flamm, R. E., and R. M. Harris-Warrick (1986b) Aminergic modulation in lobster stomatogastric ganglion. II. Target neurons of dopamine, octopamine, and serotonin within the pyloric circuit. J. Neurophysiol. 55:866-881

Harris-Warrick, R. M. (1988) Chemical modulation of central pattern generators. In Neural Control of Rhythmic Movements in Vertebrates, A. H. Cohen, S. Rossignol, and S. Grillner, eds., pp. 285-331, Wilcy, New York.

Hooper, S. L., and E. Marder (1984) Modulation of a central pattern generator by two neuropeptides, proctolin and FMRFamide. Brain Res. 305: 186-191.
Hooper, S. L., and E. Marder (1987) Modulation of the lobster pyloric rhythm by the peptide proctolin. J. Neurosci. 7: 2097-2112.

Katz, P. S., and R. M. Harris-Warrick (1987) Serotonergic primary sensory neurons feed back to motor neurons in the crab stomatogastric ganglion. Soc. Neurosci. Abstr. 13: 821.

Marder, E. (1987) Neurotransmitters and neuromodulators. In The Crustacean Stomatogastric System. A Model for the Study of Central Nervous Systems, A. I. Selverston and M. Moulins, eds., pp. 263300, Springer, Heidelberg.

Marder, E., and J. S. Eisen (1984) Electrically coupled pacemaker neurons respond differently to same physiological inputs and neurotransmitters. J. Neurophysiol. 51: 1362-1374.

Marder, E., S. L. Hooper, and K. K. Siwicki (1986) Modulatory action and distribution of the neuropeptide proctolin in the crustacean stomatogastric nervous system. J. Comp. Neurol. 243: 454-467.

Marder, E., R. L. Calabrese, M. P. Nusbaum, and B. Trimmer (1987) Distribution and partial characterization of FMRFamide-like peptides in the stomatogastric nervous systems of the rock crab, Cancer borealis, and the spiny lobster, Panulirus interruptus. J. Comp. Neurol. 259: 150-163.

Miller, J. P. (1987) Pyloric mechanisms. In The Crustacean Stomatogastric System. A Model for the Study of Central Nervous Systems, A. I. Selverston and M. Moulins, eds., pp. 109-136, Springer, Heidelberg.

Miller, J. P., and A. I. Selverston (1982) Mechanisms underlying pattern generation in lohster stomatogastric ganglion as determined by selective inactivation of identified neurons. II. Oscillatory properties of pyloric neurons. J. Neurophysiol. 48: 1378-1391.

Nagy, F., and P. S. Dickinson (1983) Control of a central pattern generator by an identified modulatory interneurone in crustacea. I. Modulation of the pyloric motor output. J. Exp. Biol. 105: 33-58.

Nagy, F., P. D. Dickinsun, and M. Moulins (1981) Modulatory effects of a single neuron on the activity of the pyloric pattern generator in Crustacea. Neurosci. Lett. 23: 167-173.

Nagy, F., J. A. Benson, and M. Moulins (1985) Cholinergic inputs reduce a steady outward $\mathrm{K}^{+}$current allowing activation of a $\mathrm{Ca}^{2+}$ conductance which underlies the burst-generating oscillations in lobster pyloric neurons. Soc. Neurosci. Abstr. 11: 1022.

Nusbaum, M. P., and E. Marder (1987) A newly identified modulatory proctolin-containing neuron (MP neuron) in the stomatogastric nervous system of the crab Cancer borealis. Neurosci. Abstr. 13: 1257.

Pitman, R. M., C. D. Tweedle, and M. J. Cohen (1973) The form of nerve cells: Determination by cobalt impregnation. In Intraccllular Staining in Neurobiology, S. B. Kater and C. Nicholson, eds., pp. 8397, Springer-Verlag, Heidelberg.

Raper, J. A. (1979) Nonimpulse mediated synaptic transmission during the generation of a cyclic motor program. Science 205: 304-306.

Rezer, E., and M. Moulins (1983) Expression of the crustacean pyloric pattern generator in the intact animal. J. Comp. Physiol. A 153: 1728.

Robertson, R. M., and M. Moulins (1981) Oscillatory command input to the motor pattern generators of the crustacean stomatogastric ganglion. I. The pyloric rhythm. J. Comp. Physiol. A. 143: 453-463.

Russell, D. F., and D. K. Hartline (1981) A multiaction synapse evoking both EPSPs and enhancement of endogenous bursting. Brain Res. 223: $19-38$

Selverston, A. I., and M. Moulins, eds. (1987) The Crustacean Stomatogastric System: A Model for the Study of Central Nervous Systems, 330 pp., Springer-Verlag, Heidelberg.

Sigvardt, K. A., and B. Mulloney (1982) Properties of synapses made by IVN command-interneurones in the stomatogastric ganglion of the spiny lobster Panulirus interruptus. J. Exp. Biol. 97: 153-168. 